\title{
PROSECUTOR VERSUS JEAN-PIERRE BEMBA GOMBO: O TRIBUNAL PENAL INTERNACIONAL E A RESPONSABILIDADE DO COMANDO
}

\author{
PROSECUTOR VERSUS JEAN-PIERRE BEMBA GOMBO: THE INTERNATIONAL CRIMINAL COURT \\ AND COMMAND RESPONSIBILITY
}

Geziela Iensue

Resumo: A responsabilidade de comando implica a responsabilidade do superior pelo descumprimento de agir para impedir condutas penais de seus subordinados. O superior é responsável tanto por sua falta de controle e autoridade no evento em que se cometem os crimes quanto por condutas penais alheias. O princípio da responsabilidade de comando, consagrado no artigo 28 do Estatuto de Roma, tem se convertido em um dos mais relevantes mecanismos de Direito Penal Internacional e de Direito Internacional Humanitário com vistas a combater a impunidade de crimes internacionais. No presente artigo pretendeu-se analisar a decisão do caso do político congolês Jean-Pierre proferido recentemente pelo Tribunal Penal Internacional (TPI), enfatizando-se o pioneirismo da fundamentação sob o princípio da responsabilidade de comando. Para tanto, apresentou-se a evolução da jurisdição penal internacional frente ao redimensionamento da ideia clássica de soberania e da responsabilização dos agentes estatais em face da proteção aos direitos humanos. Procurou-se discu- tir a natureza jurídica da responsabilidade superior a partir da problematização do caráter peculiar da imputação ao superior consistente em uma omissão. Por fim, circunscreveu-se a análise do caso Jean-Pierre Bemba Gombo, buscando-se evidenciar a relevância do julgado e suas inúmeras inovações, notadamente, a responsabilização penal do "superior de comando" fundada no princípio da responsabilidade do comando, cujas tropas promoveram crimes internacionais, mesmo que não os tenha diretamente ordenado ou estado no local, bem como o entendimento igualmente pioneiro daquela Corte quanto à violência sexual ser considerada um crime contra a humanidade. Conclusivamente, sustentou-se que a referida decisão representou um avanço em relação ao fim da impunidade e a toda forma de injustiça.

Palavras-chave: Tribunal Penal Internacional. Estatuto de Roma. Responsabilidade do comando.

\footnotetext{
Doutora em Direito pela Universidade Federal do Paraná; Mestre em Ciências Sociais Aplicadas pela Universidade Estadual de Ponta Grossa; Pesquisadora-bolsista de Desenvolvimento Científico Regional do CNPq/Fundect vinculada ao Mestrado em Direitos Humanos da Fundação Universidade Federal de Mato Grosso do Sul; Professora Voluntária da Universidade Federal de Mato Grosso do Sul; Av. Costa e Silva, s/n - Cidade Universitária, Campo Grande - MS, 79070-900; igeziela@ gmail.com
} 


\begin{abstract}
The command responsibility entails the superior responsibility for the act of failure to prevent criminal conduct of its subordinates. The superior is responsible both for its lack of control and authority in the event in which crimes are committed and for others' criminal conduct. The principle of command responsibility in article 28 of the Statute of Rome has become one of the most important mechanisms of international criminal law and International Humanitarian Law in order to combat impunity for international crimes. This article aimed to analyze the decision in the case of the Congolese politician Jean-Pierre delivered recently by the International Criminal Court (ICC), emphasizing the pioneering of the foundation under the principle of command responsibility. It presented the evolution of international criminal jurisdiction before the resizing of the classical idea of sovereignty and accountability of state agents in the face of human rights protection. It was sought to discuss the legal nature of superior responsibility from questioning the peculiar character of the imputation to the superior consistent in an omission. Finally, it was circumscribed the analysis of Jean-Pierre Bemba Gombo's case seeking to prove the relevance of the trial and its numerous innovations, notably the criminal liability of the "superior command" founded on the principle of command responsibility, whose troops promoted international crimes, even if they were not directly ordered or been on site, as well as the equally pioneer understanding of that Court in relation to sexual violence been considered a crime against humanity. Conclusively, it was argued that the decision represented an improvement over the end of impunity and all forms of injustice.
\end{abstract}

Keywords: International Criminal Court. Rome Statute. Command responsibility.

\title{
Introdução
}

A constituição de Tribunais Internacionais é decorrente da fase de jurisdicionalização do Direito Internacional contemporâneo. No instante em que se enaltece a tendência jurisdicionalizante do jus gentium a sociedade internacional propugna a criação de tribunais internacionais voltados à resolução das diversas controvérsias existentes na seara das relações internacionais.

Nesse momento, a criação de Tribunais Penais Internacionais ad hoc com competência para julgar crimes internacionais considerados graves representou uma nova possiblidade quanto à efetiva responsabilidade individual penal internacional.

Com efeito, desde o final da Primeira Guerra Mundial, a sociedade internacional ansiava pela criação de uma Corte penal internacional capaz de fortalecer e salvaguardar os direitos humanos em nível global.

A noção de um jus puniendi em âmbito mundial em relação àqueles crimes que podem atingir a humanidade como um todo e comprometer a dignidade humana, notadamente, após as duas Guerras Mundiais, começa efetivamente a integrar a agenda internacional dos Estados.

Diante das inúmeras objeções aos Tribunais ad hoc das Nações Unidas e face à antiga aspiração da sociedade internacional quanto à criação de um tribunal penal permanente com jurisdição universal, no que se refere às violações de direitos humanos, foi instituído, em 1998, por meio do Estatuto de Roma, o Tribunal Penal Internacional (TPI).

A partir de então, ganhou fôlego a teoria da responsabilidade penal internacional do indivíduo, na medida em que se previu a responsabilização individual daqueles praticantes de ilícitos internacionais previstos no Estatuto, e não somente de Estados. ${ }^{1}$

\footnotetext{
1 Nesse diapasão, cabe mencionar a célebre passagem do julgamento do Tribunal de Nuremberg ao frisar a relevância da responsabilização penal dos acusados de violações internacionais graves: " [...] crimes against international law are committed by
} 
Nesse diapasão, o Estatuto de Roma do Tribunal Penal Internacional incorpora, em seu artigo 28, sob o título da "responsabilidade dos chefes militares e outros superiores hierárquicos", a previsão da denominada "responsabilidade de mando ou de comando".

Considerando a magnitude e atrocidade dos crimes cometidos no atual cenário em conflitos internacionais, e bem assim, o recurso recorrente a esse tipo de responsabilidade, requer-se, portanto, cada vez mais a formulação de critérios específicos à sua aplicação.

Destarte, nos termos do então artigo em comento, nas alíneas $(a)$ e (b), o superior hierárquico será criminalmente responsável pelos crimes de competência do Tribunal que tiverem sido cometidos por subordinados sob a sua autoridade e controle efetivos, pelo fato de não ter exercido um controle apropriado sobre esses subordinados.

Conforme o entendimento exposto por inúmeros julgados dos Tribunais Internacionais, os requisitos suficientes à responsabilidade do comando circunscrevem-se a que os crimes cometidos por seus subordinados, isto é, os chamados crimes-base, constituam resultado da inobservância do dever de controle efetivo que compete ao chefe ou superior hierárquico.

Com vistas a melhor compreender as referidas peculiaridades que envolvem o "princípio da responsabilidade do comando", no presente artigo pretendeu-se analisar a decisão do caso do político congolês Jean-Pierre Bemba Gombo, proferida em data de 21 de março do ano corrente, pelo Tribunal Penal Internacional, face à Operação 2002-2003, ocorrida na República Centro-africana. Buscou-se enfatizar o pioneirismo da Corte Penal Internacional em relação à fundamentação da responsabilidade individual do Sr. Bemba Gombo, a partir da aplicação do princípio da "responsabilidade de comando".

Para tanto, faz-se na primeira seção uma breve e necessária discussão da consagração da jurisdição penal internacional frente ao redimensionamento dos conceitos clássicos do Direito Internacional Público, qual sejam, a ideia de soberania tradicional e a responsabilidade dos agentes estatais frente à urgente salvaguarda dos direitos humanos.

Em seguida, passa-se à problematização da definição e da natureza jurídica da responsabilidade penal internacional, notadamente, a partir da consagração do princípio da responsabilidade do comando pelo Estatuto de Roma. Ademais, verifica-se o tratamento da omissão em suas tipicidades objetiva (actus reus) e subjetiva (mens rea) no âmbito da responsabilidade individual do superior, disciplinada no artigo 28, (a) do Estatuto de Roma.

Originalmente, como será visto, a omissão foi tratada como participação por omissão, e somente a partir do Estatuto de Roma pode ser qualificada como crime independente. Destaca-se, portanto, a evolução da responsabilidade penal individual tanto no Direito Penal Internacional quanto no Direito Internacional Humanitário.

men, not by abstract entities, and only by punishing individuals who commit such crimes can the provisions of international law of be enforced." "Crimes contrários ao direito internacional são cometidos por homens e não por entes abstratos e somente a punição a estes indivíduos garantirá a aplicabilidade destas normas." (ARGIRÓ, 1946 apud LATTANZI; MONETTI, 2006, p. 79, tradução nossa). 
Por fim, no presente artigo se circunscreveu a análise do caso Prosecutor versus Jean-Pierre Bemba Gombo, que esteve, inclusive, sob a presidência da juíza brasileira Sylvia Steiner, evidenciando as suas inúmeras inovações, como o foco da decisão da Corte Penal na violência sexual usada como arma de guerra, considerada crime contra a humanidade. Além disso, a responsabilização penal do "superior militar de comando" cujas tropas promoveram crimes atrozes, mesmo que não tenham ordenado diretamente o cometimento dos referidos crimes ou estado no local no momento do evento.

Conforme o entendimento esposado pelos juízes da Câmara de Julgamento III, a responsabilização nesse caso se justifica em razão do descumprimento das medidas que o condenado, em decorrência da sua posição à época, tinha o dever de adotar. Conclusivamente, sustentar-se que a atuação do Tribunal Penal Internacional no presente caso representou, sem dúvida, um avanço em relação ao fim da impunidade, ou seja, a toda forma de negação dos direitos e injustiças.

\section{A jurisdição penal internacional e a soberania}

A instituição do Tribunal Penal Internacional - Cour Pénale Internationale ou International Criminal Court - visou atender ao anseio histórico da sociedade internacional relativo à existência de um tribunal com competência para o julgamento de graves crimes contra os direitos humanos, bem como corrigir diversas distorções verificadas em relação a Tribunais criados precedentemente com tal escopo.

A nova Corte criminal vinculada à Organização das Nações Unidas (ONU), criada pelo Tratado de Roma, aprovado em 17 de julho de 1998, ${ }^{2}$ e com sede em Haia, na Holanda, detém com-

2 A sua criação foi festejada pela comunidade jurídica, especialmente, aquela mais estreitamente relacionada com os Direitos Humanos. 
petência para julgar os denominados crimes de genocídio, ${ }^{3}$ crimes contra a humanidade, ${ }^{4}$ bem como os crimes de guerra ${ }^{5}$ e os crimes de agressão. ${ }^{6}$

Sua criação representou um avanço importante no que se refere à responsabilização dos governantes, dos chefes militares e mesmo de pessoas comuns pela prática desses delitos, especialmente face à revisão do conceito tradicional de soberania.

De um ponto de vista histórico, a ideia de soberania encontra-se intrinsicamente vinculada à noção de poder ou submissão, ou seja, "dominis potest dei", segundo a célebre afirmação de São Paulo. A expressão soberania, do latim super omnia ou supremitas, equivale a superior ou à qualidade dos domínios que dependem apenas de Deus. ${ }^{7}$

Embora a noção de soberania tenha sido claramente afirmada e teoricamente definida desde o início do século XVI, parece persistir, ainda, certa dificuldade em precisá-la. É comum notar a falta de unanimidade entre os muitos estudiosos que se dispõem a defini-la.

A noção de soberania como o poder incontrastável e ilimitado do Estado, acima do qual não há nenhum outro, parece ter acompanhado ao longo dos séculos parte significativa de suas conceituações. No século XIX tais características aparecem frequentemente jungidas à figura do monarca e à sua forma de poder, passando, posteriormente, a vincular-se ao Estado.

Nesse diapasão, o seu conceito clássico persistiu incólume até meados da segunda metade do século XX, ${ }^{8}$ quando ocorre a internacionalização dos direitos humanos, e começa a ganhar eco

\footnotetext{
3 Para os efeitos do ER, [...] entende-se por "genocídio" quaisquer dos atos adiante elencados praticados com a intenção de destruir, no todo ou em parte, um grupo nacional, étnico, racial ou religioso, enquanto tal: o homicídio de membros do grupo; ofensas graves à integridade física ou mental de membros do grupo; sujeição intencional do grupo a condições de vida com vistas a provocar a sua destruição física, total ou parcial; imposição de medidas destinadas a impedir nascimentos no seio do grupo; transferência, à força, de crianças do grupo para outro grupo (BRASIL, 2002).

4 Está-se diante de um artigo muito extenso do Estatuto de Roma, assim, serão destacadas apenas as condutas incorridas por Jean-Pierre Bemba Gombo e que serviram de base à sua condenação inovadora, são elas: "[...] entende-se por 'crime contra a humanidade', qualquer um dos atos seguintes, quando cometido no quadro de um ataque, generalizado ou sistemático, contra qualquer população civil, havendo conhecimento desse ataque: a) Homicídio; [...] g) Agressão sexual, escravatura sexual, prostituição forçada, gravidez forçada, esterilização forçada ou qualquer outra forma de violência no campo sexual de gravidade comparável; [...]" (BRASIL, 2002, grifo nosso).

5 Diante da mesma razão exposta na nota anterior, destacam-se os seguintes crimes de guerra: "c) Em caso de conflito armado que não seja de índole internacional, as violações graves do artigo 30 comum às quatro Convenções de Genebra, de 12 de Agosto de 1949, a saber, qualquer um dos atos que a seguir se indicam cometidos contra pessoas que não participem diretamente nas hostilidades, incluindo os membros das forças armadas que tenham deposto armas e os que tenham ficado impedidos de continuar a combater devido à doença, lesões, prisão ou qualquer outro motivo: i) Atos de violência contra a vida e contra a pessoa, em particular o homicídio sob todas as suas formas, as mutilações, os tratamentos cruéis e a tortura; e) As outras violações graves das leis e costumes aplicáveis aos conflitos armados que não têm caráter internacional, no quadro do direito internacional, a saber qualquer um dos seguintes atos: v) Saquear um aglomerado populacional ou um local, mesmo quando tomado de assalto; vi) Cometer atos de agressão sexual, escravidão sexual, prostituição forçada, gravidez à força, tal como definida na alínea $\mathrm{f}$ do parágrafo 20 do artigo 7o; esterilização à força ou qualquer outra forma de violência sexual que constitua uma violação grave do artigo 3o comum às quatro Convenções de Genebra." (BRASIL, 2002, grifo nosso).

6 O ER deixou em suspenso a questão da tipificação de crime de agressão em virtude de tamanha controvérsia sobre a sua inclusão, preferiu estabelecer a definição em momento posterior (artigos 121 e 123, do Estatuto de Roma). Em 2010, aconteceu a Conferência de Revisão em Kampala, Uganda, quando foi aprovada a Resolução RC/Res 6, dispondo não apenas da tipificação do crime de agressão, da atuação do Tribunal Penal Internacional quando da ocorrência do delito. Segue o artigo 8 bis, $\iint 1^{\circ}$ e $2^{\circ}$ do ER estabelecendo que, por "ato de agressão" "[...] se considera o uso da força armada por um Estado que viole a soberania, a integridade territorial ou a independência política de outro país, ou ainda que perpetre qualquer ação que seja incompatível com a Carta das Nações Unidas [...]" (INTERNATIONAL CRIMINAL COURT, 2016).

7 Doutrina de Santo Agostinho ao sustentar a submissão dos reis frente ao poder espiritual do Papa.

8 Esse conceito tem sido revisto por modelos teóricos do denominado Direito Comunitário, cujas ideias de cooperação e integração regional têm conduzido a uma concepção completamente nova do Estado, e consequentemente de soberania.
} 
na seara internacional a tese da possível relativização da "soberania" frente à proteção da dignidade humana.

Destarte, pode-se afirmar que, até o pós-Segunda Guerra Mundial, muito pouco se progrediu, internacionalmente, no que se refere a coibir graves e vultosas violações aos direitos humanos. Notadamente, porque prevalecia o entendimento de que os governantes, no exercício da soberania do Estado, eram juridicamente irresponsáveis por suas ações.

Cabe sublinhar que a doutrina da irresponsabilidade dos governantes procura legitimar quaisquer atos por estes praticados, sob a alegação de defesa dos interesses superiores estatais.

No contexto, evidencia-se que a noção da inimputabilidade dos governantes, todavia, arraigada na cultura política desde a antiguidade, somente adquiriu contornos doutrinários em 1513, com Nicolau Maquiavel (MACHIAVELLI, 1940, p. 120). Ademais, a referida ideia ganhou contornos jurídicos com a clássica obra, escrita em 1576 por Jean Bodin, intitulada Os seis livros da República, cuja soberania fora descrita como um poder absoluto e perpétuo do Estado (BODIN, 1961, p. 122).

Com efeito, tal concepção de soberania como um poder ilimitado e/ou divino dos reis, pouco a pouco, foi sendo aperfeiçoada. Pode-se notar um grau maior de sofisticação nas teorizações dos seus defensores desde os albores da modernidade. ${ }^{9}$

Durante vários séculos a doutrina da irresponsabilidade dos agentes estatais não sofrera maiores transformações. Arrimada sobre a ideia clássica de soberania, somente começa a se modificar defronte às indizíveis e brutais atrocidades ocorridas durante a Primeira ${ }^{10}$ e a Segunda ${ }^{11}$ Guerras Mundiais (KEEGAN, 1995, p. 370-377).

Com a utilização de novas armas de extermínio e de destruição em massa pelas potências beligerantes, tanto em campo quanto fora dele, tais conflitos mundiais levaram ao aniquilamento de milhões de pessoas. Assim, nesse contexto de barbárie, foi dado o primeiro passo concreto no sentido de responsabilizar os dirigentes políticos e militares acusados de cometer crimes contra a humanidade ${ }^{12}$ e crimes contra a paz ou guerra de agressão, todos considerados contrários às normas internacionais.

A despeito das críticas comumente feitas às Cortes penais provisórias, como a provisoriedade, parcialidade, suspeição - vez que criadas por meio de Resoluções da ONU - a violação de princípios basilares do direito penal, como a legalidade, anterioridade, juiz natural, seletividade na condução de julgamentos internacionais, ${ }^{13}$ entre outros, fato concreto é que foram instaurados o Tribunal de Nüremberg e o Tribunal de Tóquio.

\footnotetext{
9 Exemplificativamente Richelieu (2016). Jellinek (2013) compreendia a soberania a partir da ideia de autolimitação, ou seja, a vontade do Estado de se autodeterminar e de se auto-obrigar por meio da Constituição e da produção legislativa. Tal vontade capaz de estabelecer, por si própria, a esfera de sua ação não pode se subordinar jamais a outras vontades, apresentando-se, assim, como um poder ilimitável e ilimitado.

10 Ocorreu o aniquilamento de cerca de 15 milhões de indivíduos. Digno de nota no contexto, houve o massacre, em 1915 , de cerca de um milhão de armênios pelos turcos.

11 Estima-se que pereceram mais de 55 milhões de pessoas.

12 Os crimes contra a humanidade, em virtude de sua amplitude, compreendiam o genocídio, a escravidão, os homicídios em massa e outros delitos correlatos.

13 Tal seletividade impediu, exemplificativamente, a investigação e a punição do ditador e líder do Khmer Vermelho Saloth Sar, também conhecido como Pol Pot, pelo massacre de mais de um milhão de cambojanos, na década de 1970. Recorda-se
} 
Tais Cortes criminais provisórias tinham por objetivo a apuração das atrocidades cometidas pelos nazistas no Holocausto e pelas autoridades políticas e militares do Japão Imperial durante a Segunda Guerra Mundial, respectivamente. Ambos os Tribunais rejeitaram as escusas apresentadas pelos vencidos, arrimadas em fundamentos de atos de soberania, necessidade militar e cumprimento de ordens superiores com vistas a escaparem da punição.

A criação de um Tribunal Penal Internacional competente para julgar as violações de direitos humanos em um plano global tornou-se cada vez mais premente, especialmente após a aprovação de diversos documentos internacionais, v.g., a Convenção para a Prevenção e a Repressão do Crime de Genocídio, de 1948, as Convenções de Genebra, de 1949, a Convenção sobre a Imprescritibilidade dos Crimes de Guerra e dos Crimes de Lesa Humanidade, de 1968.

Tal ideia foi também reafirmada expressamente no parágrafo 92 da Declaração e Programa de Viena, de 1993. ${ }^{14}$ Mencionadas experiências, contudo, não conseguiram dissuadir os muitos criminosos de guerra, que continuaram a agir impunemente durante as inúmeras contendas ocorridas a partir da segunda metade do século XX.

A situação de completa impunidade perdurou até a instauração de dois Tribunais ad hoc, um foi instalado na antiga Iugoslávia, em 1993, em virtude da questão envolvendo sérvios contra croatas e demais etnias, ${ }^{15}$ e outro, no ano 1994, em Ruanda, cujo território foi palco do massacre da nação tutsi pelos extremistas hutus, visando fazer cessar e punir os gravíssimos abusos cometidos em ambos os conflitos (SEIDERMAN, 2001, p. 23-25). ${ }^{16}$

Em seguida, a sociedade internacional resolveu instituir uma corte penal permanente com vistas a contornar as diversas objeções apresentadas em relação a todos esses Tribunais provisórios criados anteriormente. A Corte Penal Internacional foi criada por meio do instrumento internacional aprovado em 17 de julho de 1998, o denominado Tratado de Roma. ${ }^{17}$

Com a assinatura deste, os conceitos tradicionais de Direito Internacional Público e mais precisamente de soberania são abalados, posto que os Estados concordem em exportar parte de sua soberania em favor de instituições internacionais capazes de editar normas supranacionais.

Frisa-se no contexto que o mencionado instrumento internacional foi assinado pela República Federativa do Brasil em 07 de fevereiro de 2000, aprovado pelo Decreto Legislativo n. 112 de 2002 e promulgado pelo Decreto Presidencial n. 4.388, de 25 de setembro de 2002.

que a instalação de um Tribunal ad hoc dependia de decisão do Conselho de Segurança da ONU, no qual cinco Estados têm o poder de veto.

14 Parágrafo 92 da Declaração e Programa de Viena in verbis (1993): "[...] a Conferência Mundial sobre Direito Humanos recomenda [...] e encoraja a Comissão de Direito Internacional a continuar seus trabalhos visando o estabelecimento de um tribunal penal internacional."

15 A experiência do Tribunal Ad hoc na Ex-Iugoslávia, julgou o ex-presidente da Sérvia, Slobodan Milosevic, acusado de genocídio durante a Guerra da Bósnia, serviu para reforçar a necessidade de criação de um tribunal penal internacional permanente junto à $\mathrm{ONU}$, para o julgamento de crimes contra a humanidade.

16 interessante na atuação destes tribunais foi a produção da tese do julgamento de indivíduos que praticaram crimes em conflitos considerados de caráter interno, que até então não se enquadravam na normativa penal internacional.

17 Estatuto de Roma divide-se em 13 capítulos, os quais versam sobre a criação da Corte (Cap. I), sua competência, a admissibilidade e o direito aplicável (Cap. II), Princípios Gerais de Direito Penal (Cap. III), composição e administração do TPI (Cap. IV), inquérito e procedimento criminal (Cap. V), julgamento (Cap. VI), penas (Cap. VII), recurso e revisão (Cap. VIII), cooperação internacional e auxílio judiciário (Cap. IX), execução da pena (Cap. X), Assembleia dos Estados-partes (Cap. XI), financiamento (Cap. XII) e cláusulas finais (Cap. XIII) (BRASIL, 2002). 
Cabe sublinhar que a própria Constituição da República Federativa do Brasil de 1988, em seu texto original, já aderira à ideia da criação de um Tribunal Penal Internacional, dispondo expressamente no artigo $7^{\circ}$ do Ato das Disposições Constitucionais Transitórias que "[...] o Brasil propugnará pela formação de um tribunal internacional dos direitos humanos." (BRASIL, 1988).

A Emenda Constitucional n. 45, de 30 de dezembro de 2004, veio a acrescer ao artigo $5^{\circ}$ do Texto Constitucional um $\ 4^{\circ}$, que dispõe expressamente que o Brasil "[...] se submete à jurisdição de Tribunal Penal Internacional a cuja criação tenha manifestado adesão." (BRASIL, 1988).

Trata-se da primeira instituição jurisdição penal global dotada das características de permanência e universalidade. Aliás, cabe assinalar que, a partir do momento em que um Estado assume os compromissos mútuos firmados no Estatuto de Roma, cujas normas se revestem de uma natureza centrífuga, ele está concordando em autorrestringir sua soberania em prol da proteção de todo e qualquer ser humano. ${ }^{18}$

Importa destacar que, a despeito do propalado redimensionamento da noção clássica de soberania estatal, duas ideias parecem ainda subsistir, quais sejam, a independência na ordem externa e a supremacia na ordem interna. Por conseguinte, para alguns teóricos, qualquer intervenção externa, ainda que para salvaguardar os direitos humanos, confronta-se de modo irremediável com a soberania nacional, a qual pressupõe não intervenção em assuntos internos.

Entretanto, sustenta-se aqui que os Estados-Partes, ao cooperarem para a aplicação das normas consagradas no Estatuto de Roma, ao invés de estarem comprometendo a sua soberania, estão, na verdade, afirmando-a, em prol da proteção dos direitos humanos, e do próprio cidadão, finalidade maior de ser do Estado.

Evidencia-se que uma das principais inovações alvissareiras do Tratado de Roma reside na consagração do princípio, segundo o qual a responsabilidade penal por ações violadoras das normas de direito internacional deve recair sobre o sujeito que as perpetrou, deixando de prevalecer ou restando afastadas possíveis imunidades, privilégios ou limitações de ordem internacional decorrentes da posição, cargo ou função estatal que porventura ostente.

Com efeito, os crimes de competência do TPI são cometidos justamente por esses sujeitos, cujas salvaguardas conferidas geralmente por seus ordenamentos jurídicos internos thes permitem invocar a imunidade de jurisdição.

Por conseguinte, sustenta-se aqui a tese de que a característica do caráter superior ou supremo da soberania não equivale a poder estatal ilimitado. $O$ Estado, e mais propriamente os seus governantes, constituem apenas um instrumento revelador do Direito, a quem cabe determinar e aplicar, ao qual se encontram igualmente submetidos.

O exercício da soberania não pode servir de escudo para que governantes tripudiem sobre os direitos mais caros à humanidade; deve, portanto, servir de instrumento coletivo para assegurá-los. Suas ações tornam-se legítimas à medida que assegure e defenda tais direitos.

18 Tal noção encontra fundamento jurídico no artigo 27 da Convenção de Viena sobre Direito dos Tratados, que concede primazia às convenções internacionais face ao direito interno (BRASIL, 2009). 
Nesse passo, em razão da atuação universal do TPI, sendo este pessoa jurídica de direito internacional e dispondo de independência, posto que lhe faculta o funcionamento sem que experimente quaisquer ingerências de ordem externa ou de ordem jurídica interna de qualquer Estado.

E, inclusive, pode demandar sujeitos nacionais de Estados não partes do Estatuto; defende-se no presente artigo a tese segundo a qual a normativa do Tratado de Roma não se submete ao estabelecido nas ordens jurídicas internas dos Estados, mas ao Direito Internacional que, nesse caso, passa a ser aplicado diretamente.

O funcionamento do Tribunal Penal Internacional, ao contrário das cortes internacionais em geral, não depende de qualquer consentimento do Estado quanto à sua competência jurisdicional, em decorrência da sua automaticidade. A competência ratione materiae da Corte Internacional Penal abrange, como já se noticiou, os seguintes crimes, imprescritíveis: crime de genocídio, crimes contra a humanidade, crimes de guerra e crime de agressão.

Frisa-se, porém, que a competência desse Tribunal, no que se refere aos referidos ilícitos, somente alcança aqueles cometidos após a entrada em vigor do Estatuto no Estado-Parte. Destaca-se, contudo, o seu caráter complementar e subsidiário às jurisdições penais nacionais. Assim, a jurisdição internacional somente deverá intervir - subsidiariamente, como ultima ratio, caso haja omissão por parte da jurisdição penal interna ou haja persecução criminal insuficiente. ${ }^{19}$

Outro ponto a ser destacado no Tratado de Roma é a incorporação do artigo 28 que estabelece a previsão da responsabilidade do superior ou de comando. A referida responsabilidade será objeto de análise do próximo item.

\section{0 artigo 28 do estatuto de roma e a responsabilidade do comando}

A doutrina da responsabilidade do comando, embora remonte ao século XVI, como já mencionado, ainda na contemporaneidade não logrou êxito em melhor definir os contornos dos elementos que a compõem.

Considerando a complexidade e a amplitude dos conflitos internacionais existentes no contexto atual, assim como a utilização cada vez mais frequente dessa espécie de responsabilização, torna-se premente a formulação de critérios objetivos e subjetivos mais precisos e específicos ao seu recurso.

Referida espécie de responsabilização, embora tenha origem que remonta ao século XVI e se sustente em norma consolidada do direito costumeiro, somente obteve positivação e clara vinculação com a responsabilidade penal, notadamente, com as decisões do pós-guerra. Tais julgamentos serviram de supedâneo tanto à positivação da doutrina quanto à elaboração dogmática. ${ }^{20}$

Desde então, até os recentes julgados dos tribunais ad hoc para a antiga Iugoslávia (TPII) e Ruanda (TPIR), os requisitos da responsabilidade de comando assumiram diferentes matizes.

\footnotetext{
19 Conforme os critérios definidos no artigo 17 do próprio Estatuto de Roma.

20 O Protocolo Adicional I às Convenções de Genebra (1949), aprovado em 1977, estabeleceu pela primeira vez a doutrina da responsabilidade penal do comando (GREENWOOD, 2004, p. 599).
} 
Os pressupostos de sua amplitude, com pretensão de validade geral, foram codificados pioneiramente pelo artigo 28 do Estatuto de Roma. Todavia, embora tal dispositivo se pretenda exaustivo em virtude de décadas de intensas construções jurisprudenciais e doutrinárias, os seus elementos formadores estão longe de ser claros e uniformes.

A responsabilidade do comando, conforme preconiza a doutrina command responsability, firma-se por omissão. O superior é penalmente responsável em decorrência da ausência de controle e supervisão dos que lhe são subordinados no evento em que cometam ilícitos. Em outras palavras, há responsabilidade do superior hierárquico quando este se furta a impedir as condutas delitivas de seus subordinados (AMBOS; CARVALHO, 2005, p. 159).

Destaca-se que a espécie de responsabilidade penal por omissão aqui mencionada é ímpar no direito penal internacional. Em observância à doutrina francesa que não reconhece a responsabilidade geral por omissão imprópria - posto que interpreta estritamente o princípio da legalidade -, afastou-se do artigo 28 a previsão geral proposta no projeto do Estatuto.

A partir desta premissa de que a responsabilidade do comando se estabelece por omissão, avança-se no sentido de analisar se a disposição em comento representa um crime de omissão própria ou imprópria (AMBOS; CARVALHO, 2005, p. 299-300).

Valendo-se do critério formal ou critério do tipo penal, pode-se afirmar que o artigo 28 constitui um crime impróprio por omissão, isso porque, à semelhança do que preconiza o $\int 2^{\circ}$ do artigo 13 do Código Penal Brasileiro, não se vislumbra no presente dispositivo um tipo penal ou chamado Tatbestand, mas uma norma limitadora de responsabilidade oriunda de um dever de garantia.

Ademais, a imputação ao superior pelos crimes-base cometidos por seus subordinados, como descreve o critério do tipo de omissão imprópria, resulta da combinação de uma cláusula geral, ou seja, o artigo 28 do Estatuto, com o tipo penal específico atinente a um crime comissivo, constantes nos artigos $6^{\circ}$ a $8^{\circ}$ do mesmo diploma normativo. ${ }^{21}$

Face à peculiaridade da tese da responsabilidade do superior, alguns teóricos sustentam que há uma contradição entre a conduta culposa do comandante e o dolo direto (intenção) do subordinado quanto à comissão das condutas, ou seja, uma comissão de um crime doloso por negligência. ${ }^{22}$

Outros ainda argumentam que tal contradição se revela aparente, pois o crime de responsabilidade de comando do artigo 28 e os crimes-base dos subordinados consistem em normas que guardam independência entre si, com distintos elementos subjetivos. ${ }^{23}$

\footnotetext{
21 Segundo pontuam Ambos e Carvalho (2005), cumpre não confundir a responsabilidade como superior e como partícipe. O superior deve apenas conhecer ou poder conhecer os crimes-base, enquanto o partícipe deve ainda almejar a sua ação de participação e em especial também a ação principal. Ao se fazerem presentes os requisitos de uma responsabilidade por participação, a responsabilidade do superior assume apenas um caráter subsidiário.

22 Esse é entendimento de Schabas e Carvalho (2005), segundo os quais, o superior descumpre culposamente o seu dever de controle adequado dos subordinados que, consequentemente, cometem ilícitos dolosos consoantes ao artigo 30 do ETPI.

23 O primeiro caso refere-se à violação de um dever de supervisão apropriada que pode ser cometida tanto na modalidade dolosa quanto na culposa; o segundo caso, por sua vez, refere-se aos crimes cometidos com dolo, conforme prevê o artigo 30 do EPTI (AMBOS; CARVALHO, 2005, p. 300). Nesse sentido aduz Greenwood (2004, p. 599) que, no caso da responsabilidade do superior, este é punido em razão da ausência de controle daqueles sob o seu comando, e não pela participação nos crimes por eles cometidos.
} 
Com efeito, a distinção entre a ordem para cometer delitos com previsão no artigo 25(3)(b) com a responsabilidade do superior. Algumas vozes da doutrina e também alguns julgados, inclusive recentes, insistem em defender que ordenar o cometimento de crimes e/ou faltar ao dever de impedi-los, constituem, na verdade, duas faces da mesma questão.

Do ponto de vista fático, tais posições até se justificam, vez que geralmente os casos de responsabilidade do comando acompanham-se de ordens para a prática de delitos - a direct command responsability. Caso as ordens não possam ser provadas ou atribuídas ao superior, é comum o reconhecimento de um tipo subsidiário de responsabilidade penal do superior - fall back liability.

Evidencia-se que, conforme se depreende da redação do artigo 28 do Estatuto de Roma, é fundamental à doutrina da responsabilidade do comando a existência de uma relação de subordinação. Além disso, não basta apenas existir a inter-relação superior-subordinado, faz-se necessária, ainda, a presença de uma cadeia de comando (BANTEKAS, 1999, p. 5, 578; WILLIAMSON, 2002, p. 2; ZAHAR, 2001, p. 609).

Assim, para os efeitos da responsabilidade de comando, é preciso que a relação de subordinação subsista dentro de uma estrutura hierarquicamente organizada, cuja estratificação se centra na autoridade exercida por aqueles que a compõem.

O superior participante da relação de subordinação inserida em uma cadeia de comando, independente de seu nível hierárquico, deve exercer cumulativamente a autoridade, seja de jure seja de facto, o controle efetivo sobre os subordinados. ${ }^{24}$ Portanto, deve adotar as medidas adequadas, necessárias ${ }^{25}$ e razoáveis ${ }^{26}$ ao seu alcance ${ }^{27}$ com vistas a reprimir, prevenir ou informar as autoridades competentes. $^{28}$

Destarte, deve existir uma relação de causalidade entre a omissão do superior e a conduta lesiva dos subordinados. Todavia, para que se possa verificar a presença ou ausência do nexo causal, faz-se necessária a eleição de um conceito de causalidade, entre aqueles apresentados pelas diversas teorias sobre a temática.

Visando a elucidar o requerimento causal estabelecido pelo artigo 28, a doutrina penal internacional adota com certa preponderância a denominada teoria da equivalência das condições (conditio sine qua non) ${ }^{29}$ Algumas críticas são apontadas à adoção da referida teoria, quanto à sua capacidade de fornecer o melhor substrato à análise da causalidade atinente à responsabilidade do comando. ${ }^{30}$

\footnotetext{
24 Sublinha-se que a doutrina da responsabilidade do comando se restringe às organizações cujas finalidades são legítimas, e cujos membros cometem delitos excepcionalmente. Raciocínio baseado na semelhança entre o artigo 28 e o artigo 7 (3) do Estatuto de Roma (ZAHAR, 2001, p. 611-612).

25 A expressão "necessária" refere-se a indispensável, essencial. Portanto, medida indispensável à defesa do bem ameaçado ou à punição do agressor que já lesou o bem.

26 O termo "razoável" implica a medida proporcional à ação do agressor.

27 A expressão "ao alcance" diz respeito à medida adequada e necessária que esteja à disposição do superior, no contexto fático cuja ação se desenvolve.

28 Para efeitos de investigação e procedimento criminal, Ambos e Carvalho (2005, p. 207).

29 Conforme afirma D'Ávila (2001, p. 21-23), a teoria da equivalência das condições encerra fragilidades no que pertine às hipóteses de causalidade alternativa e causalidade hipotética, especialmente ao tratar da responsabilidade do superior. Ademais, o autor evidencia, também, problemas de amplitude ilimitada e de equívoco lógico-metodológico na fórmula de eliminação hipotética.

30 Alguns autores indicam que a teoria da imputação objetiva conduz a resultados mais satisfatórios. A respeito, ver Jescheck (1993, p. 258), Escamilla (apud D’ÁVILA, 2001, p. 40-41) e Frisch (apud D’ÁVILA, 2001, p. 43).
} 
A partir da análise dos termos do artigo 28, alíneas $a$ e $b,{ }^{31}$ a norma estabelece uma relação causal entre o descumprimento do superior e o cometimento de crimes por parte dos subordinados. Assim, uma vez localizado o resultado do crime-base, basta relacioná-lo com a omissão do superior, mediante um nexo causal, cuja falta acarreta a impossibilidade de imputação dele. ${ }^{32}$

Salienta-se, o destinatário da norma contida no artigo 28 que prevê a responsabilidade dos "[...] comandantes militares e outros superiores hierárquicos pelas condutas delitivas de suas forças ou subordinados" (BRASIL, 2002) deve, necessariamente, ser um "superior". Tal questão adquire especial relevo no momento em que se requer indicar dentro de uma relação de subordinação e cadeia de comando quem são os sujeitos suscetíveis à punição pelas ações de outros. ${ }^{33}$

O dispositivo em comento reconhece, ainda, a extensão da responsabilidade de comando aos superiores civis, incluindo-os expressamente em sua redação, bem como elencou critérios distintos em relação ao elemento subjetivo (mens rea) do superior hierárquico militar e do superior hierárquico não militar, qual seja, civil. ${ }^{34}$

Ambos os superiores, militares e civis, poderão ser responsabilizados pelos delitos de seus respectivos subordinados em duas situações, veja-se. No que se refere aos primeiros, se "sabiam" ${ }^{55}$ ("knew" / "conhecimento efetivo") ou deveriam saber, ${ }^{36}$ se as condutas delitivas estavam sendo cometidas ou prestes a sê-las.

Em relação aos segundos, estes responderão pelos crimes cometidos pelos seus subordinados nas hipóteses em que conheciam ou deliberadamente desconsideraram informação que indicava claramente (consciously disregarded information which clearly indicated) que os seus subordinados se preparavam ou estavam cometendo os crimes. ${ }^{37}$

\footnotetext{
31 "O superior hierárquico será criminalmente responsável pelos crimes da competência do Tribunal que tiverem sido cometidos por subordinados sob a sua autoridade e controle efetivos, pelo fato de não ter exercido um controle apropriado sobre esses subordinados." (BRASIL, 2002, grifo nosso).

32 Na próxima seção se vê que a corte manifestou entendimento distinto quanto ao critério adequado à configuração do nexo de causalidade, ao se tratar especificamente do caso Jean-Pierre Bemba Gombo.

33 Embora o artigo 28 mencione expressamente "superior", a interpretação que se atribui é no sentido de que a responsabilidade do superior prescinde de qualquer limitação hierárquica. Os julgados, não obstante, serem vacilantes, em certa medida, indicam que o superior deve pertencer ao "nível de condução" (TPN), "poder de autoridade" (TPII) ou "poder hierárquico" (TMI - Extremo-Oriente).

34 É primeira vez no direito penal internacional que ocorre a codificação do elemento subjetivo, o qual passa a ser requerimento geral à responsabilidade pena individual (WERLE; JESSBERG, 2005, p. 35).

35 De acordo com o artigo 30 (3) do Estatuto, que se aplica também aos civis neste caso, "conhecimento" refere-se à "[...] consciência de que existe uma circunstância ou de que um efeito terá lugar, em uma ordem normal dos acontecimentos." (BRASIL, 2002). A jurisprudência tem entendido que não bastam meras presunções, são necessárias evidências circunstanciais (AMBOS; CARVALHO, 2005, p. 208-209).

36 O significado da expressão "deveria ter conhecido" (should have known) se aplica somente em relação ao militar. Segundo D'Ávila (2001, p. 104), ela corresponde à culpa inconsciente ou infração de cuidado devido, quando o agente atua negligentemente de modo descuidado, ignorando por completo a possível ocorrência de resultado típico. A responsabilidade ocorre, em razão do descumprimento das medidas, que em decorrência da sua posição hierárquica tinha o dever de adotar (D'ÁVILA, 2001, p. 104).

37 O artigo 30 do ETPI preceitua que "[...] salvo disposição em contrário, nenhuma pessoa poderá ser criminalmente responsável e punida por um crime de competência do Tribunal, a menos que atue com vontade de cometer e conhecimento de seus elementos materiais." A persecução criminal de superiores civis se mostra mais dificultosa, especialmente em razão da dificuldade de produção probatória.
} 
Diante da ausência de especificação pelo artigo 28 em apreço em relação à motivação do superior, pode-se concluir que o critério em comento abarca tanto a culpa consciente quanto o dolo eventual (D'ÁVILA, 2001, p. 104; AMBOS; CARVALHO, 2005, p. 217). ${ }^{38}$

Nesse diapasão, se o superior não considerar livremente a informação que indicava claramente que os subordinados estavam a cometer ou se preparavam para fazê-lo, acreditando que o resultado típico não ocorrerá, ele age com culpa consciente.

Frisa-se que o artigo 28 (b) (i) pressupõe que o superior portava a informação, mas a desconsidera deliberadamente, ${ }^{39}$ já aqui ele tem conhecimento das ofensas cometidas ou prestes a acontecer, portanto, não se pode cogitar a ausência de previsão do resultado típico pelo superior. Resta, portanto, afastada a aplicação de culpa inconsciente aos superiores civis, consolidando-se como pertencente exclusivamente aos militares.

De outro modo, caso o superior, ao deliberadamente desconsiderar informação que indicava de maneira clara que os subordinados estavam a cometer ou se preparavam para cometer os delitos, fazê-lo por não se importar com a realização do resultado típico, estará configurada hipótese de dolo eventual.

Recorda-se que, em ambos os casos, há previsão do resultado e assunção do risco de produzi-lo. O que os distingue substancialmente é que na culpa consciente o agente não admite o resultado como possível, e no dolo eventual o agente consente com o resultado, este lhe é indiferente.

Assim, se o superior deliberadamente não considerar a informação que indicava claramente que os subordinados estavam a cometer ou se preparando para cometer as ofensas, fazê-lo porque não se importa com a realização dos crimes-base (resultado típico), agirá com dolo eventual. Entretanto, se o fizer porque não acredita que o resultado típico se produzirá, estará agindo com culpa consciente.

Embora se afirme que presentes os requisitos objetivos e subjetivos cumulativamente, resta-se configurada a responsabilidade do superior, esta ainda é objeto de intensos debates, visto que seus elementos objetivos e subjetivos ainda carecem de clareza e melhor definição.

Resumidamente, o artigo 28 do Estatuto de Roma prevê a responsabilidade penal do superior hierárquico pelos delitos de competência do Tribunal que tiverem sido cometidos por subordinados, sob o seu controle e autoridade efetiva, em virtude da inobservância de dever de controle suficiente que lhe cumpria sobre esses mesmos subordinados.

\section{A relevância da decisão do caso prosecutor versus Jean-Pierre Bemba Gombo}

Estatuto de Roma buscou estabelecer alguns princípios de direito para que possam servir de base à responsabilização penal de indivíduos na seara internacional. A doutrina menciona os princípios nullum crimen e nulla poena sine lege; irretroatividade, juiz natural, complementaridade,

\footnotetext{
38 Para melhores esclarecimentos quanto à distinção entre culpa inconsciente e culpa consciente e entre esta e o dolo eventual, conferir Jescheck (1993, p. 516).

39 O superior possui representação da possível ocorrência do resultado típico, pois detém a informação nesse sentido.
} 
imprescritibilidade, responsabilidade penal internacional individual, irrelevância da função oficial, responsabilidade de comandantes e outros superiores, entre outros.

Considerando a análise proposta no presente artigo cingir-se, especialmente à responsabilidade do comando, trata-se aqui dos três últimos princípios mencionados enfatizando o princípio da responsabilidade de comandantes e outros superiores, o denominado princípio do comando.

A Corte Internacional Penal rege-se pelo princípio da responsabilidade penal internacional individual, o qual dispõe que apenas indivíduos, pessoas naturais, poderão ser julgadas por esse Tribunal. Mencionada norma tem como alicerce a Resolução das Nações Unidas, de 1946 (AMBOS; CHOUKR, 2000, p. 32).

O princípio da irrelevância de função oficial evidencia a noção de que não importa se o indivíduo, no momento em que cometeu a conduta lesiva ou posteriormente, ocupava cargo ou função oficial, pois será do mesmo modo responsabilizado. Tal princípio já fora utilizado pelos distintos Tribunais ad hoc, como foi anteriormente visto.

Tribunal Penal Internacional poderá também responsabilizar chefes militares, ou ainda outros superiores, por atos, ações ou omissões realizados por meio de seu comando, assim como preconiza o princípio da responsabilidade de comandantes e outros superiores.

O veredicto do leading case Jean-Pierre Bemba Gombo pode ser considerado histórico, posto que se trata da primeira vez que a Corte Internacional Penal impõe condenação a alguém fundada no "princípio do comando" ou "da responsabilidade superior".

Em 21 de março de 2016 os juízes entenderam de modo unânime que o acusado deveria ser considerado penalmente responsável, como chefe militar, pelos delitos cometidos por suas tropas que atuaram sob o seu controle e comando.

O político congolês não somente falhou na responsabilidade de prevenir os crimes que foram cometidos por seus subordinados, bem como não os puniu pelo cometimento das violações sistemáticas, sendo, por esse motivo, ele próprio condenado pelos crimes. A investigação do Tribunal Penal Internacional teve início em 22 de maio de 2007, após o Estado Centro-Africano recorrer à Procuradoria do TPI em 2004.

No ano 2002, o Presidente em exercício do Estado Centro-Africano, Ange-Félix Patassé, solicitou ao grupo armado liderado por Jean-Pierre Bemba Gombo - o Movimento para a Libertação do Congo (MLC) da República Democrática do Congo ${ }^{40}$ - para intervir na República Centro-Africana, com vistas a impedir uma tentativa de golpe por François Bozizé.

O Movimento para a Libertação do Congo (MLC) foi acusado de promover uma devastadora campanha de mortes, torturas e estupros na República Centro-Africana no período de 2002 a 2003. Bemba era o então chefe do MLC e integrava a comitiva do ditador Mobutu, visto que posteriormente se tornou Vice-presidente do Governo de transição da República Democrática do Congo (RDC) de 2003 a 2006.

40 O País Centro-Africano foi cenário de uma guerra civil entre 1998 e 2003 que dizimou mais de três milhões de pessoas pela fome, violência e doenças. A nação abriga mais de 250 grupos étnicos disputando poder e riquezas presentes no território. 
Contra ele, foram feitas três acusações por crimes de guerra, homicídios, violações e pilhagens, e duas acusações de crimes contra a humanidade, homicídio e estupro. Todos esses crimes teriam sido alegadamente cometidos enquanto aquele ocupou o cargo de Chefe Militar.

O primeiro político a ser condenado pelo Tribunal Penal Internacional teve sua prisão efetivada na Bélgica, onde estava exilado, em 24 de maio de 2008, sendo mais tarde transferido para o Centro de Detenção da Haia, em 03 de julho do mesmo ano.

No dia seguinte após a detenção, o investigado foi conduzido perante os juízes da Câmara de Questões Preliminares pela primeira vez. Durante a audiência, verificou-se a identidade do investigado e lhe foram esclarecidos todos os fatos e crimes a ele imputados, assim como lhe foram informados os seus direitos garantidos pelo Estatuto de Roma, incluindo o pedido de liberdade provisória até o julgamento.

Em 30 de março de 2009, o Prosecutor apresentou a acusação, incluindo a responsabilidade de comando prevista no artigo 28 cumulativamente à alegação de responsabilidade penal individual do artigo 25 (3) alínea (a), ambos do Estatuto de Roma.

Instaura-se e ação penal, e Jean-Pierre Bemba Gombo comparece perante a Câmara de Julgamento (SPC) II. Esta confirma, entre 12 e 15 de julho de 2009, as acusações de crimes de guerra e crimes contra a humanidade cometidos na RCA entre 2002 e 2003, submetendo o acusado a julgamento.

A defesa procurou sustentar a incompetência do Tribunal e questionou a admissibilidade da acusação. Procurou argumentar que somente as Cortes da África Central detinham competência para julgar o chefe militar, e que estas já haviam decidido em não prosseguir com a persecutio criminis contra a pessoa em causa, bem como o caso não era suficientemente grave para justificar a ulterior intervenção do TPI.

Além disso, a defesa procurou sustentar fortemente que o ex-Vice-presidente não tinha conhecimento do que se passava do outro lado da fronteira, vez que a milícia a qual comandava havia sido enviada, no ano 2002, para a República Centro-Africana. Portanto, o procedimento perante aquela Corte estaria inquinado por vários vícios de legalidade.

Tais alegações foram afastadas pelo juízo de admissibilidade, que decidiu reconhecer a admissibilidade do caso perante a Corte Penal, em junho de 2010, decisão esta que foi confirmada pela Câmara de Recursos em outubro de 2010. O julgamento teve início em 22 de novembro de 2010 e contou com a participação, por meio de representante legal, de aproximadamente cinco mil vítimas.

Paralelamente, e nos primeiros dias após a detenção em Haia de Jean-Pierre, a defesa permaneceu tentando obter a liberdade condicional do acusado; tais tentativas restaram inexitosas, tanto na fase da investigação quanto na fase do julgamento.

Entre 2011 e 2013 ocorreu a instrução probatória, sendo apresentadas evidências, provas documentais, bem como foram ouvidas inúmeras testemunhas de defesa e, principalmente, testemunhas de acusação, e colhido um número significativo de depoimentos das vítimas. ${ }^{41}$

41 Por volta de 2.287 vítimas em 15 de dezembro de 2011, muitos de seus depoimentos foram colhidas por meio de videoconferência. No total do procedimento foi autorizado a participar no caso Jean-Pierre Bemba Gombo, um total de 5.229 vítimas. 
As alegações finais foram apresentadas no final de 2014. Destaca-se, nesse lapso temporal, a suspensão do julgamento determinada pela SPI III, em 13 de dezembro de 2012 até 04 de março de 2013, em virtude da mudança pelos juízes quanto ao entendimento da extensão da "responsabilidade dos superiores".

Os juízes do SPI III sinalizaram que o elemento da responabilidade penal de Bemba como responsável superior derivada de seu "conhecimento de que os crimes eram cometidos" poderia mudar para "deveria saber que os crimes eram cometidos".

Em 21 de março de 2016, a Câmara de Julgamento III, composta pelos juízes Sylvia Steiner (Presidente), Kuniko Ozaki e Joyce Aluch, nos termos do artigo 74 (2) do Estatuto de Roma, declarou por unanimidade culpado Jean-Pierre Bemba Gombo, sob o artigo 28 item (a) (i e ii) desse Diploma Legal, tendo este agido como um comandante militar, infringido os crimes previstos no artigo 7 (1) itens (a) e (g); artigo 8 (2) item (c), alínea (i); item (e), alíneas (v e vi).42

Portanto, Bemba foi condenado pelo cometimento de três crimes de guerra, qual sejam, homicídio, violação e pilhagem, e dois crimes contra a humanidade, homicídio e violação sexual, especificamente, estupro. ${ }^{43}$

A Sessão de Julgamento III expressamente reconheceu que o artigo 28, alínea (a) refere-se à responsabilidade do comandante militar, assim como se estende à pessoa que efetivamente atua como comandante militar ou desempenha ou não funções exclusivamente militares.

E que a posição de Bemba à época dos fatos se enquandrava na última situação descrita, ou seja, era uma pessoa agindo efetivamente como um comandante militar (TRIAL CHAMBER, 2016a, p. 345), que sabia que as forças do MLC sob a sua autoridade e controle efetivos estavam a cometer ou se preparavam para cometer os crimes praticados, conforme já havia argumentado o Prosecutor. ${ }^{44}$

Nesse diapasão, os juízes consideraram que o congolês atuou como comandante militar e dispunha de autoridade efetiva e controle sobre os integrantes do Mouvement de Libération Du Congo (MLC) contra a população civil na República Centro-Africana durante o período de 26 de outubro de 2002 a 15 de março de 2003.

A Corte considerou, com base nas provas produzidas, que Bemba tinha conhecimento de que suas "tropas" estavam a cometer ou prester a cometer os crimes contra a humanidade e de guerra (INTERNATIONAL CRIMINAL COURT, 2016, p. 347, tradução nossa).

\footnotetext{
A Corte ouviu até o encerramento do julgamento por volta de 77 testemunhas.

42 Íntegra da decisão, International Criminal Court (2016).

43 "The Chamber finds beyond reasonable doubt that Mr. Bemba is criminally responsible under Article 28(a) for the crimes against humanity of murder and rape, and the war crimes of murder, rape, and pillaging committed by his forces in the course of the 2002-2003 CAR Operation." A Câmara entendeu que, para além de qualquer dúvida razoável, Bemba devevia ser penalmente responsável nos termos do artigo 28 (a) pelos crimes contra a humanidade de homicídio e estupro, bem como pelos crimes de guerra de homicídio, estupro, e pilhagens cometidos por suas forças no curso da Operação 2002-2003 CAR (INTERNATIONAL CRIMINAL COURT, 2016, p. 359).

44 "Article 28(a) not only provides for the liability of military commanders, but also extends to "person[s] effectively acting as military commander[s]" - the latter being, in the submission of the Prosecution, the appropriate characterization of Mr. Bemba's position in the case." "O artigo 28 (a), não só prevê a responsabilidade dos comandantes militares, mas também se estende a(s) 'pessoa(s) efetivamente atuando como comandante(s) militar(s)' - sendo este último, no entendimento do Promotor, a situação da posição do senhor Bemba no caso." (INTERNATIONAL CRIMINAL COURT, 2016, p. 83, tradução nossa).
} 
E a despeito de exercer autoridade e controle eficaz sobre as "forças" do MLC, não tomou as medidas necessárias e adequadas ${ }^{45}$ ao seu alcance, com vistas a prevenir ou reprimir ${ }^{46}$ a prática destes crimes por suas tropas, ou levou o assunto às autoridades competentes ${ }^{47}$ para a investigação e punição durante a Operação 2002-2003.48

Ademais, a falha do comandante no cumprimento de suas obrigações para prevenir, reprimir ou levar ao conhecimento das autoridades competentes pela investigação e julgamento incrementou o risco da comissão pelas tropas. ${ }^{49}$

Vislumbrou ainda, na esteira da interpretação que tem sido dada pelo TPI, diferentemente do entendimento dos Tribunais ad hoc, prescindindo de um nexo de causalidade necessário entre a omissão do superior quanto ao seu dever de exercer um controle efetivo e os crimes-base cometidos por seus subordinados.

\footnotetext{
45 "His primary intention was not to genuinely take all necessary and reasonable measures within his material ability to prevent or repress the commission of crimes, as was his duty." "Sua intenção principal era não tomar deliberadamente nenhuma das medidas necessárias e adequadas a sua capaciade material de prevenir ou reprimir o cometimento de crimes, como era seu dever." (INTERNATIONAL CRIMINAL COURT, 2016, p. 354, tradução nossa).

46 "Mr. Bemba could have, inter alia, ensured that the MLC troops in the CAR were properly trained in the rules of international humanitarian law, and adequately supervised during the 2002-2003 CAR Operation; (ii) initiated genuine and full investigations into the commission of crimes, and properly tried and punished any soldiers alleged of having committed crimes; (iii) issued further and clear orders to the commanders of the troops in the CAR to prevent the commission of crimes; (iv) altered the deployment of the troops, for example, to minimize contact with civilian populations; (v) removed, replaced, or dismissed officers and soldiers found to have committed or condoned any crimes in the CAR; and/ or (vi) shared relevant information with the CAR authorities or others and supported them in any efforts to investigate criminal allegations." Bemba poderia ter, inter alia, assegurado o treinamento das tropas do MLC na RCA quanto às regras do direito internacional humanitário, e à adequada vigilância durante a Operação 2002-2003 CAR; (ii) iniciado genuínas investigações sobre a prática de crimes, e devidamente julgar e punir soldados que tiverem cometido tais crimes; (iii) emitido claramente ordens aos comandantes das tropas do CAR para impedir a prática de crimes; (iv) alterado o envio de tropa com vistas a minimizar o contato dos oficiais com as populações civis; (v) remover, substituir, ou demitir os subordinados que tiverem cometido ou toleradado qualquer crime no CAR; e/ou (vi) compartilhado as informações relevantes com as autoridades competentes e apoiá-los e empreender quaisquer esforços para investigar as alegações criminais." (INTERNATIONAL CRIMINAL COURT, 2016, p. 358, tradução nossa).

${ }_{47}$ "There is no evidence that Mr. Bemba took any measures in response to information transmitted internally within the MLC of crimes by MLC soldiers from, for example, the MLC intelligence services or the leads uncovered during the Mondonga Inquiry, Zongo Commission, or Sibut Mission." "Não há nenhuma evidência que o Sr. Bemba tomou quaisquer medidas à transmissão de informações internamente dentro do MLC dos crimes cometidos por soldados do MLC a partir, por exemplo, dos serviços de inteligência para o MLC ou as descobertas durante a investigação de Mondonga, Comissão Zongo, ou Missão Sibut." (INTERNATIONAL CRIMINAL COURT, 2016, p. 358, tradução nossa).

${ }_{48}$ "The Accused was a person effectively acting as a military commander and had effective authority and control over the MLC forces that committed the crimes." "[...] the Accused knew that the MLC forces were committing or about to commit the crimes." "[...] the Accused failed to take all necessary and reasonable measures to prevent or repress the commission of the crimes or to submit the matter to competent authorities for investigation and prosecution." "[...] the crimes were committed as a result of the Accused's failure to 'exercise control properly' over the MLC forces." "O acusado era uma pessoa agindo efetivamente como um comandante militar e tinha autoridade eficaz e controle sobre as forças do MLC que cometeram os crimes." "[...] O acusado sabia que as forças do MLC estavam a cometer ou se preparavam para cometer os crimes." "[...] O acusado não tomou todas as medidas necessárias e razoáveis para prevenir ou reprimir a prática dos crimes ou para levar o assunto às autoridades competentes para a investigação e repressão." "[...] Os crimes foram cometidos como resultado da falha do acusado de ter exercido o controle corretamente 'sobre as forças do MLC." (INTERNATIONAL CRIMINAL COURT, 2016, p. 341-365, tradução nossa).

49 "Mr. Bemba's failure to fulfil his duties to prevent crimes increased the risk of their commission by the MLC troops in the CAR." A Câmara observa que, a jurispruência dos tribunais ad hoc define "comissão por subordinados" no contexto de responsabilidade superior, como sendo incorporar os modos de responsabilidade para além da "comissão" em sentido estrito, v.g., planejar, instigar, auxiliar, ou ser cúmplice. Na matéria conferir os seguintes casos: United Nations (2007, paras. 485 a 486) e International Criminal Tribunal For The Former Yugoslavia (2008a). Ver, ainda, International Criminal Tribunal For The Former Yugoslavia (2008b, para. 371), United Nations (2004, para. 91), United Nations (2001, paras. 252 e 303), International Criminal Tribunal For The Former Yugoslavia (2003, paras. 362 a 363) e International Criminal Tribunal For The Former Yugoslavia (2013, para. 398).
} 
Isso bastou para ensejar a responsabilidade penal nos termos do artigo 28 alínea (a), que a omissão do comandante aumentou o risco da prática dos crimes cometidos pelos subordinados. ${ }^{50}$

No que se refere à "condenação cumulativa", a Corte admitiu a possibilidade, para além de qualquer dúvida razoável, que o Sr. Bemba é penalmente responsável nos termos do artigo 28 (a) por estupro, considerado este tanto um crime de guerra quanto um crime contra a humanidade. Admitiu, também, a condenação por homicídio, considerado, do mesmo modo, um crime de guerra e um crime contra a humanidade (TRIAL CHAMBER III, 2016b).

Para isso, a Câmara de Jugamento precisou analisar a admissibilidade da cumulação dessas condenações com base na mesma conduta subjacente, não obstante a existência de distintas infrações. O Tribunal decidiu que não haveria o denominado ne bis in idem previsto no artigo 20 do Estatuto (INTERNATIONAL CRIMINAL COURT, 2016, p. 356), em virtude da existência de infrações com elementos materialmente distintos, isto é, o foco está sobre se cada crime exigiu a prova de um fato não exigido pelo outro.

A pena a ser executada e as reparações às vítimas serão decididas pelo TPI após a audiência suplementar. Tanto a Promotoria do TPI quanto a defesa do condenado poderão interpor recurso à Câmara de Apelação, no prazo de 30 dias, conforme preceitua o artigo 150 das regras de procedimento e evidência da Corte.

Consequentemente, em relação à responsabilidade penal, o TPI entendeu pela incidência, in casu, do já analisado princípio do comando ou princípio do comando responsável, admitindo a responsabilidade pessoal de Bemba Gombo com base no artigo 28, item (a) do Estatuto de Roma.

Assim, esse julgado pode ser considerado particular e sem precedentes por vários aspectos, pois pela primeira vez na história do TPI um comandante que atua como militar é condenado por crimes cometidos pelas tropas que liderava, mesmo que não os tenha ordenado, em um país terceiro.

Sublinha-se que Jean-Pierre Bemba Gombo não se encontrava na República Centro-Africana quando ocorreram os crimes que lhe estavam sendo imputados. $\bigcirc$ acusado foi julgado não como autor ou coautor, mas enquanto "superior militar", sob o princípio da "responsabilidade do comando".

Ademais, a sentença condenatória do antigo Vice-presidente da República Democrática do Congo reveste-se também de suma importância, no que se refere ao pioneirismo quanto à condenação pelo cometimento de delitos de violência sexual, especificamente o estupro, ${ }^{51}$ qualificado como crime de guerra.

\footnotetext{
50 A juíza Sylvia Steiner manifestou entendimento em voto separado, referente ao critério high probability ser mais adequado à caracterização do grau de risco, do que apenas a probabilidade de que ausência de controle efetiva pelo comandante poderia ter evitado o cometimento dos crimes pelos subordinados. Senão, veja-se: "[...] in my opinion, the causality requirement would be satisfied where, at least, there is a high probability that, had the commander discharged his duties, the crime would have been prevented or it would have not been committed by the forces in the manner it was committed." (TRIAL CHAMBER III, 2016b).

51 Na esteira da jurisprudência do Tribunal Penal Internacional para a antiga Iugoslávia, o TPI entendeu que, além da penetração vaginal e anal, o estupro abrange também atos de penetração oral, capazes de causar humilhações e traumas de intensidade equivalente e ferir a dignidade humana.
} 
No particular, os juízes procuraram destacar que as evidências coletadas durante a instrução demonstraram que os atos de violência sexual cometidos pelo MLC naquele contexto estavam imbuídos de motivação específica e objetivos claros, ${ }^{52}$ configurando-se, portanto, como armas de guerra.

Essa decisão pode auxiliar e contribuir à sensibilização sobre as consequências que tais delitos atrozes perpetrados em larga escala no âmbito de conflitos armados não internacionais, isto é, internos, acarretam às vidas das vítimas que sofrem com atos dessa natureza. ${ }^{53}$

\section{Conclusão}

Como visto, a Primeira Guerra Mundial impulsionou a criação de um tribunal penal, de alcance internacional, em virtude do crescimento de um repúdio internacional às atrocidades cometidas durante aquele período de beligerância, que a história denominou "Guerra Mundial".

Entretanto, o acontecimento decisivo para a consolidadção da responsabilidade penal individual, no âmbito internacional, e o estabelecimento das exceções às imunidades funcionais atribuídas aos oficiais e autoridades de alto escalão, em caso de violações graves do Direito Internacional, ocorreu após a Segunda Guerra Mundial, com a instituição dos Tribunais ad hoc dos aliados Nuremberg e Tóquio e a consagração de um novo ideário.

Foi possível a punição de indivíduos específicos, e não apenas organizações ou Estados, o que representou um grande avanço em relação ao sistema do Tratado de Versalhes. Ademais, essa responsabilidade penal individual passou a ser admitida a despeito dos mecanismos baseados em atos de soberania ou em princípios de ordem hierárquica.

O período que se segue da Segunda Guerra Mundial até a década de 1980 foi bastante profícuo para o desenvolvimento do Direito Penal Internacional. Destarte, os Tribunais Penais Internacionais para a ex-Iugoslávia e para a Ruanda, a Conferência de Viena de 1993 sobre os Direitos Humanos, contribuíram fortemente para o estabelecimento de uma jurisidição criminal internacional, implicando a criação, em 1998, do Tribunal Penal Internacional (TPI).

Por conseguinte, a sua criação demonstra a afirmação contemporânea de um anseio clássico, ou seja, a efetividade de uma jurisdição penal internacional. Também representa uma velha aspiração da sociedade internacional, qual seja, um tribunal permanente competente para julgar acusados da prática de crimes que configurem genocídio, crimes de guerra, de agressão e crimes contra a humanidade.

Buscou-se evidenciar, ainda, no presente artigo, que a tese de que a característica do caráter superior ou supremo da soberania não equivale a poder estatal ilimitado. O Estado, e mais propria-

\footnotetext{
52 As vítimas dos ataques eram consideradas "prêmios de guerra" por terem derrotado o "inimigo", bem como as agressões sexuais tinham por finalidade humilhar, desestabilizar e punir simpatizantes dos grupos opositores.

53 A Corte reconheceu que houve uma política a informar sobre ataques à população civil levada a cabo pelo MLC, caracterizando uma espécie de modos operandi. "Moreover, consistent with evidence of a modus operandi, most of the crimes were committed when the MLC was the only armed group in the area." (INTERNATIONAL CRIMINAL COURT, 2016, p. 358, tradução nossa).
} 
mente os seus governantes, constituem apenas um instrumento revelador do Direito, a quem cabe determinar e aplicar, ao qual se encontram igualmente submetidos.

Logo, o exercício da soberania não pode servir de escudo para que governantes tripudiem sobre os direitos mais caros à humanidade; deve, portanto, servir de instrumento coletivo assegurá-los. Suas ações tornam-se legítimas à medida que assegure e defenda tais direitos.

Nesse sentido, surge, pois, um novo sistema jurídico internacional com a finalidade de salvaguardar a humanidade de novas atrocidades ou condutas lesivas cometidas por indivíduos em oposição ao Direito Internacional.

Com efeito, também se tratou aqui da resposabilidade dos "superiores", que pode ser tanto por ação (comissão) quanto por omissão. Destacou-se que os limites da responsabilidade penal por omissão nao estão claramente definidos no direito penal. Do ponto de vista do Direito Internacional Humanitário, a responsabilidade penal do superior é considerada uma espécie de participação na comissão do crime.

A jurisprudência dos Tribunais penais internacionais ad hoc tem indicado que a imputação de responsabilidade a um superior por não cumprir o seu dever de agir deve considerar os crimes cometidos por seus subordinados. Assim, o superior não é responsável como se ele mesmo tivesse praticado o crime, todavia, considera-se sua responsabilidade proporcionalmente à gravidade das infrações cometidas.

Os julgados das Cortes também procuram esclarecer e delinear os requisitos necessários à responsabilização do superior. Particularmente, a jurisprudência tem sinalizado que prescinde ao superior o desempenho de jure de uma posição hierárquica, bastando o exercício de fato. Assim, se determinar por meio da aplicação do critério do "controle efetivo", se o superior tem poderes reais para controlar os atos dos seus subordinados, com vistas a saber se este tem capacidade material de evitar e punir a conduta criminal.

Destarte, a qualificação militar também não se mostra necessária, podendo atribuir responsabilidae penal a um político ou civil pela comissão de crimes de guerra cometidos por seus liderados. Quando restar desmonstrado que o superior civil tinha conhecimento ou deliberadamente se omitiu face às informações que seus indivíduos, sob sua autoridade, estavam cometendo ou em vias de cometer os crimes da competência do TPI. Ademais, quando os crimes guardarem relação com atividades sob sua autoridade e controle efetivo.

Verificou-se que o artigo 28 do Estatuto de Roma estipula que um chefe militar ou uma pessoa que atue efetivamente como chefe militar é penalmente responsável pelos crimes cometidos pelas forças ou pessoas sob o seu mando e controle efetivo, ou sob sua autoridade e controle efetivo, quando: tenha conhecimento ou, em razão das circunstâncias do momento, deveria ter conhecimento que os subordinados estavam a cometer esses crimes ou se preparando para cometê-los; não houver adotado todas as medidas necessárias e razoáveis ao seu alcance para prevenir ou reprimir sua comissão ou para levar ao conhecimento das autoridades competentes para efeitos de sua investigação e julgamento. 
A importância da responsabilidade penal individual, notadamente, a partir da doutrina da responsabilidade do comando previsto no artigo 28 do Estatuto de Roma está amplamente reconhecida pela mais abalizada doutrina, assim como pela jurisprudência das Cortes Internacionais Criminais. Representou um avanço significativo para a evolução do Direito Penal Internacional e, mais precisamente, para o Direito Internacional Humanitário.

Destacou-se, de igual modo, que o julgamento de Jean-Pierre Bemba Gombo pelo TPI constituiu um caso particular e sem precedentes por vários aspectos, entre os quais, pela primeira vez na história dessa Corte, um indivíduo que agiu enquanto "chefe militar" é condenado por crimes cometidos pelos subordinados em um terceiro país.

Versou-se ainda do primeiro julgamento contra um ex-Vice-Presidente, e o quarto julgamento do TPI, desde a sua criação em 2002.

A decisão da Câmara de Julgamento do TPI reveste-se também de pioneirismo no que se refere à condenação de Jean-Pierre Bemba Gombo pelo cometimento de delitos de violência sexual, especificamente, o estupro, qualificado como crime de guerra.

Com efeito, a sua condenação envia uma mensagem contundente aos autores de crimes internacionais: seja qual for sua posição, função ou cargo oficial, poderão ser considerados responsáveis por seus crimes, não podendo escapar da persecutio criminis com vistas à efetivação da justiça e ao combate à impunidade.

\section{Referências}

AMBOS, Kai; CARVALHO, Salo de (Org.). O direito penal no estatuto de Roma: leituras sobre os fundamentos e a aplicabilidade do tribunal penal internacional. Rio de Janeiro: Lumen Juris, 2005.

BANTEKAS, Ilias. Principles of direct and superior responsibility in International Hummaitarian Law. Manchester: Manchester University Press, 2002.

BANTEKAS, Ilias. The contemporary law of superior responsibility. American Journal of International Law, v. 93, p. 573-595, 1999.

BODIN, Jean. Les six livres de la République. Darmstadt: Scientia Aalen, 1961.

BRASIL. Constituição. República Federativa do Brasil. Brasília, DF: Senado Federal, 1988. Disponível em: <http://www.planalto.gov.br/ccivil_03/Constituicao/Constituicao.htm>. Acesso em: 15 de abr. 2016.

BRASIL. Decreto n. 4.388, de 25 de setembro de 2002. Promulga o Estatuto de Roma do Tribunal Penal Internacional. Diário Oficial da União, Brasília, DF, 26 set. 2002. Disponível em: <http:// www.planalto.gov.br/ccivil/decreto/2002/D4388.htm>. Acesso em: 15 abr. 2016.

BRASIL. Decreto n. 7.030, de 14 de dezembro de 2009. Promulga a Convenção de Viena sobre o Direito dos Tratados, concluída em 23 de maio de 1969, com reserva aos Artigos 25 e 66. Diário Oficial da União, Brasília, DF, 15 dez. 2009. Disponível em: <http://www.planalto.gov.br/ccivil_03/_ato2007-2010/2009/decreto/d7030.htm>. Acesso em: 18 abr. 2016. 
BRASIL. Emenda Constitucional n. 45, de 30 de dezembro de 2004. Altera dispositivos dos arts. $5^{\circ}$, 36, 52, 92, 93, 95, 98, 99, 102, 103, 104, 105, 107, 109, 111, 112, 114, 115, 125, 126, 127, 128, 129, 134 e 168 da Constituição Federal, e acrescenta os arts. 103-A, 103B, 111-A e 130-A, e dá outras providências. Diário Oficial da União, Brasília, DF, 31 dez. 2004.

CHOUKR, Fauzi Hassan; AMBOS, Kay (Org.). Tribunal Penal Internacional. São Paulo: RT, 2000.

D’ÁVILA, Fábio Roberto. Crime culposo e a teoria da imputação objetiva. São Paulo: Revista dos Tribunais, 2001.

DECLARAÇÃO E PROGRAMA DE VIENA. In: CONFERÊNCIA MUNDIAL SOBRE OS DIREITOS DO HOMEM, 2., 1993, Viena. Anais... Viena, 14 a 25 jun. 1993. Disponível em: < http:// www.pge.sp.gov.br/centrodeestudos/bibliotecavirtual/instrumentos/viena.htm>. Acesso em: 25 abr. 2016.

GREENWOOD, Christopher. Command responsibility and the Hadžihasanović decision. Journal of International Criminal Justice, v. 2, i. 2, p. 598-605, 2004.

INTERNATIONAL CRIMINAL COURT. Decisão n. ICC-01/05-01/08, de 21 de março de 2016. Caso Prosecutor versus Jean-Pierre Bemba Gombo. Disponível em: <https://www.icc-cpi.int/iccdocs/doc/doc2226759.pdf>. Acesso em: 12 abr. 2016 .

INTERNATIONAL CRIMINAL COURT. Resolución RC/Res. 6. Disponível em: < http://www. icc-cpi.int/iccdocs/asp_docs/Resolutions/RC-Res.6-SPA.pdf>. Acesso em: 18 abr. 2016 b.

INTERNATIONAL CRIMINAL COURT. Trial Chamber III. Situation in the Central African Republic in the case of the Prosecutor v. Jean-Pierre Bemba Gombo. 2016. Disponível em: < https://www.icc-cpi. int/iccdocs/doc/doc2226759.pdf>. Acesso em: 12 abr. 2016.

INTERNATIONAL CRIMINAL TRIBUNAL FOR THE FORMER YUGOSLAVIA. Blagojević et al. Trial Judgment, 2008a. Disponível em: < http://www.icty.org/case/blagojevic_53/4>. Acesso em: 12 abr. 2016.

INTERNATIONAL CRIMINAL TRIBUNAL FOR THE FORMER YUGOSLAVIA. Case no. It-0142. 2003. Disponível em: <http://www.icty.org/x/cases/kovacevic_vladimir/ind/en/str-ai030331e. pdf>. Acesso em: 12 abr. 2016.

INTERNATIONAL CRIMINAL TRIBUNAL FOR THE FORMER YUGOSLAVIA. Kordić \& Čerkez. Trial Judgment, 2008b. Disponível em: < http://www.icty.org/case/kordic_cerkez/4>. Acesso em: 12 abr. 2016.

INTERNATIONAL CRIMINAL TRIBUNAL FOR THE FORMER YUGOSLAVIA. Kunarac et al. Trial Judgment, 2013. Disponível em: <http://www.icty.org/case/kunarac/4>. Acesso em: 12 abr. 2016.

JELLINEK, Georg. Teoría general del estado. 2. ed. Tradução Fernando de Los Rios. Montevideo: Editorial B de f, 2013.

JESCHECK, Hans-Heinrich. Tratado de derecho penal: parte general. 4. ed. ampl. Granada: Comares, 1993.

KEEGAN, John. Uma história da guerra. São Paulo: Companhia das Letras, 1995. 
LATTANZI, Giorgio; MONETTI, Vito. La Corte penale Internazionale: organi, competenza, reati, processo. Milano: Giuffrè Editore, 2006.

MACHIAVELLI, Nicolò. Il Principe e pagine di altre opere. Padova: CEDAM, 1940.

NYBONDAS, Maria. Civilian superior responsibility in the Kordic case. Netherlands International Law Review, p. 59-82, 2003.

RICHELIEU, Cardeal Duque de. O testamento político. Disponível em: < http://www.ebooksbrasil. org/adobeebook/richelieu.pdf>. Acesso em: 25 abr. 2016.

SCHABAS, William A. The general principles of the Rome statute. European Journal of Criminal Law, i. 6, 1998.

SEIDERMAN, Ian. Hierarchy in international law: the human rights dimension. Antuérpia: Intersentia, 2001.

UNITED NATIONS. International Tribunal for the Prosecution of Persons. Case No.: IT-95-14-A. 2004. Disponível em: <http://www.icty.org/x/cases/blaskic/acjug/en/bla-aj040729e.pdf>. Acesso em: 25 abr. 2016.

UNITED NATIONS. International Tribunal for the Prosecution of Persons. Case No.: IT-9621-A. Trial Judgment, 2001. Disponível em: <http://www.icty.org/x/cases/mucic/acjug/en/celaj010220.pdf>. Acesso em: 12 abr. 2016.

UNITED NATIONS. Mechanism for International Criminal Tribunals. Nahimana et al. (Media case) (ICTR-99-52). 2007. Disponível em: <http://unictr.unmict.org/en/cases/ictr-99-52>. Acesso em: 25 abr. 2016.

WERLE, Gehard; JESSBERG, Florian. Unless otherwise provided: article 30 of the ICC statute and the mental element of crimes under international criminal law. Journal of International Criminal Justice, i. 3, p. 35-55, 2005.

WILLIAMSON, Jamie A. Command responsibility in the case law of the International Criminal Tribunal for Rwanda. Criminal Law Forum, Dordrecht, v. 13, i. 3, 2002.

ZAHAR, Alexander. Command responsibility of civilian superiors for genocide. Leiden Journal of International Law, v. 14, p. 591-616, 2001. 
